\title{
Competencias de la docencia universitaria para la sociedad del conocimiento: la visión de tres académicos
}

El escenario educativo del siglo XXI pone en relieve la necesidad de repensar el rol docente, pasando de un contexto formativo tradicional a uno innovador que exige, como lo señala el modelo educativo de la Universidad Nacional Autónoma de Honduras (UNAH), un docente investigador en el aula, creativo ayudando a construir y ampliar las capacidades mentales de los estudiantes, ocupándose de "enseñar a pensar"; facilitador, orientador y mediador en el proceso educativo, organizador de las situaciones de aprendizaje orientadas al logro de objetivos y a la articulación de la teoría con la práctica, con un fuerte compromiso ético. En suma una docencia pertinente a las necesidades del siglo actual.

Dada la trascendencia del rol docente en el siglo XXI, en parte porque somos testigos de la Sociedad del Conocimiento y el Aprendizaje, y por otra, porque estamos frente a una nueva generación de estudiantes, durante la III Jornada de Innovación Educativa, se llevó a cabo un panel de expertos con tres académicos/ as universitarios: Rutilia Calderón, Vicerrectora Académica de la UNAH; René Noé Martínez, Director de Currículo de la Universidad Pedagógica Nacional
Francisco Morazán y Armando Euceda, Coordinador y docente de la Maestría en Física, Escuela de Física-UNAH. A continuación la Revista "UNAH INNOVA" comparte la visión de cada uno de ellos sobre las competencias del docente universitario del siglo XXI.

\section{Rutilia Calderón}

Los profesores, individual y colectivamente, tenemos una gran capacidad de impacto en los aprendizajes de los estudiantes, a enseñar se aprende enseñando.

A inicios del siglo XXI hubo serios cuestionamientos y se dijo que los factores que más condicionan el aprendizaje son los ambientes y accesos adecuados, acceso a tecnologías, bibliotecas, entre otros. Otras hipótesis sostenían que el factor principal estaba ligado a ciertas aptitudes y actitudes del estudiante. Una de las herramientas fundamentales que sustentan las ciencias (investigación) empezó a trabajar en estas hipótesis planteadas y al día de hoy hay evidencias suficientes que reafirman que el proceso de aprendizaje de los estudiantes está condicionado al docente.

Se señala que la práctica es la fuente fundamental para aprender a ser profesor. Esta es una verdad a medias, ya que es cierto que la práctica y la experiencia son parte importante del proceso, pero no lo es todo. La práctica docente posee su propia lógica, debe cumplir condiciones de calidad y pertinencia, tiene identidad sociocultural y profesional, y tiene su método propio, cosa que tal vez en nuestras universidades no ha permeado lo suficiente, y no consideramos al profesor universitario como un profesional de la educación superior.

Nuestra identidad como educadores, todavía en nuestras instituciones está más vinculada al campo científico al que pertenecemos, esa identidad como educadores está todavía en construcción.

Como profesión, la docencia requiere de conocimientos específicos, un sistema de análisis que englobe elementos teóricos y técnicos. Necesitamos un conocimiento profesional de la docencia, además de la formación en el campo disciplinar. Necesitamos ser competentes como educadores, no es suficiente serlo sólo en la disciplina y esas competencias no surgen sólo de la experiencia. 
Una competencia es saber hacer, solución indisoluble del conocimiento y la práctica. Los docentes convertimos las ideas y conocimientos en mensajes didácticos. Otro elemento clave en esta competencia, es la comprensibilidad. Otros elementos que datan de dos o tres siglos, son la capacidad de análisis y de síntesis, no podemos hacer comprensible al estudiante un conocimiento si no tenemos esas capacidades, eso hay que aprender a hacerlo.

Otra gran competencia, es el manejo de las tecnologías aplicadas a la educación superior. En la investigación de la doctora Judith Zubieta sobre "Aceptación de las TIC en la docencia. Una Tipología de los académicos de la UNAM", son interesantes los hallazgos cualitativos y cuantitativos. Se encontró que el mayor porcentaje de profesores reconocen que manejan el internet, pero más del $80 \%$ reconocen que no saben cómo usar la web para facilitar los aprendizajes de los estudiantes. Igual para los estudiantes, en 10 minutos manejan a la perfección un teléfono inteligente, pero no saben cómo usarlo para aprender. En la Universidad Nacional Autónoma de Honduras ya se trabaja en este desafío.

\section{René Noé Martínez}

¿Qué competencias asumimos al ser docente universitario? Se asume que ya lo sabemos, pero el profesor del siglo XXI es el que está dispuesto a aprender. Debemos aceptar que estamos frente a un grupo de estudiantes que juegan con ventaja. Hay aspectos, condiciones y conocimientos que ellos manejan mejor que nosotros, por ello una competencia que hay que desarrollar es la de aprender con los estudiantes.

Otro elemento, es el hecho de visualizar qué es lo que debemos saber. Hay una serie de situaciones a las que se están enfrentando los docentes: como la invasión tecnológica a la cual hay que hacerle frente, tenemos la tecnología y no podemos aislarnos de ella. El docente no debe ser experto en tecnología, pero si debe emplearla para la docencia.

La mayoría de nosotros fuimos formados en el siglo XX con toda una pedagogía del siglo XVIII y XIX y tenemos una generación del siglo XXI en el aula y queremos seguir enseñando de la forma que fuimos enseñados, tenemos que readecuar nuestras estrategias y responder de mejor forma a nuestros educandos.

Enfatizo en tres competencias que un docente jamás debe dejar a un lado: el conocimiento, pero no la repetición de los textos o de lo que otros hicieron, sino la capacidad de producir, de generar nuevos conocimientos o los cimientos de una teoría. Otra competencia es la sensibilidad hacia nuestro quehacer y el contacto cercano con el ser humano: estudiante. Una tercera competencia es el compromiso a enseñar de tal forma que vuelva cada vez más accesible el saber, el conocer, el saber hacer, la habilidad y la destreza y en desarrollar las competencias que los jóvenes necesitan para poder responder a los retos de este siglo XXI.

\section{Considero que:}

- Debemos preocuparnos por la formación permanente de nuestro profesorado y su actuali- zación.

- Hay que formar equipos y redes de docentes para fortalecer la docencia y reconocer en otros la forma de sobrepasar las debilidades y aprovechar la puesta en común de nuestras fortalezas.

- Se necesita capacitar al docente en el empleo de las tecnologías como herramientas para facilitar el aprendizaje de los educandos y enseñar a encontrar su formación ante la inundación de información.

\section{Armando Euceda}

Los docentes nos consideramos expertos en calificar lo que otros aprenden en nuestras clases, son nuestras clases y ellos son nuestros alumnos, nosotros somos los que sabemos y ellos son los que viene a nuestras aulas a aprender.

Esto tiene mucho de real, tiene mucho vínculo con lo que pasa en las universidades. Es probable que muchos docentes no lo acepten, pero es certero afirmar que en la práctica, la conducta cotidiana como docentes, demuestra lo contrario.

El problema es más complejo que la avalancha tecnológica. Los investigadores con las herramientas científicas en sus manos nos muestran que la educación entre pares, foros, wikis, textos colaborativos y en general el uso de plataformas virtuales, están desplazando a los docentes del centro del escenario educativo, para colocar a los estudiantes como actores verdaderos y creativos de su propio destino profesional. Esto no nos hace menos importantes como docentes, al contrario, nos reta a actualizarnos y desempeñar el nuevo papel de docente univer- 
sitario que requiere competencias innovadoras y demandantes.

¿Está el docente capacitado para aceptar los cambios implícitos en el nuevo paradigma de innovación educativa en la educación superior? A esta pregunta hay que agregar otra más importante: ¿está preparado el alumno para aceptar su nuevo papel, desea el cambio?

Lamentablemente el sistema educativo nuestro no educa para la independencia intelectual de nuestros jóvenes, por el contrario hemos consumado la idea de que el alumno que logra la excelencia, es aquel que es el mejor seguidor de las instrucciones del maestro, si el docente sabe lo que quiere el alumno, el alumno confía en la propuesta de cambio, el alumno prefiere la certeza a la incertidumbre.

En aras de la innovación debemos evitar la arbitrariedad, es decir, necesitamos desarrollar un estatus propio como país a nivel superior, sin descuidar el marco de referencia que imponen otras investigaciones internacionales.

Un nuevo concepto de crédito, formulado con el proyecto Tuning, en el cual se pondera con criterio nuevo el tiempo de trabajo que en la tarea invierte el alumno, más allá del tiempo invertido en la charla presencial.

Los planes de estudio nuevos deberán valorar las actividades innovadoras educativas que el docente realiza a diario en el desempeño de sus tareas. Trabajo especial se debe hacer con los alumnos para que desaparezca el fracaso en los estudios universi- tarios, imputable al cambio propuesto. El problema no está en el uso de las nuevas tecnologías, ni en la disponibilidad de las mismas, en mi opinión el problema está en la conceptualización y concreción del nuevo escenario de aprendizaje.

Herramientas tecnológicas ¿para qué?; si no sabemos para qué, no hay que inventar experimentando.

Diálogo socrático ¿para qué? si no sabemos lo que vamos a hacer con él, no lo critiquemos.

¿Plataformas virtuales, cuándo y con qué actividades? si el docente no escribe sus propias ideas en un wiki o en un blog, cómo podría convencer a los alumnos que escribir colaborativamente es importante.

Si el profesor prepara sus materiales sin dar el crédito académico correspondiente, cómo pedir a los alumnos que no hagan copiado y pegado, lo que yo hablo debe ser un reflejo de lo que yo hago.

Una competencia básica del docente en este siglo es la capacidad de hacer una planificación académica, dinámica e innovadora, que no convierta al docente y al estudiante en prisioneros de la moda tecnológica pero que de manera creativa permita sacar el máximo provecho de las tecnologías. En el modelo tradicional, una de las competencias más limitadas que el docente demuestra, tiene que ver con la evaluación, una serie de números sólo con el criterio de los maestros.
Las competencias específicas que debe tener el docente para desempeñarse en una disciplina determinada estarán en función de las competencias que exigen a los alumnos (as).

En resumen, las competencias del docente del siglo XXI parten de requerir de una formación sólida en la disciplina que cultiva, pero no se queda allí; debe establecer las relaciones cualitativas y cuantitativas que le permitan tejer, junto con sus estudiantes, conocimientos interdisciplinarios, recordando siempre que, es la innovación y la creatividad algo sustantivo y lo que nos hará cambiar en nuestra actividad docente; sin perder de vista que en el proceso educativo debemos crecer en comunión, no en contra de nuestros estudiantes. 